\title{
Review Article \\ Seminal Fluid-Mediated Inflammation in Physiology and Pathology of the Female Reproductive Tract
}

\author{
Anthonio O. Adefuye, ${ }^{1}$ Henry A. Adeola, ${ }^{2}$ Kurt J. Sales, ${ }^{3}$ and Arieh A. Katz ${ }^{3,4}$ \\ ${ }^{1}$ Division of Immunology, Department of Pathology, University of Cape Town, Faculty of Health Sciences, \\ Observatory 7925, South Africa \\ ${ }^{2}$ International Centre for Genetic Engineering and Biotechnology and Department of Integrative Biomedical Sciences, \\ Faculty of Health Sciences, University of Cape Town, Observatory 7925, South Africa \\ ${ }^{3}$ MRC/UCT Receptor Biology Research Unit, Department of Integrative Biomedical Sciences and Institute of Infectious Disease and \\ Molecular Medicine, Faculty of Health Sciences, University of Cape Town, Observatory 7925, South Africa \\ ${ }^{4}$ SAMRC Gynaecology Cancer Research Centre, Faculty of Health Sciences, University of Cape Town, Observatory 7925, South Africa
}

Correspondence should be addressed to Anthonio O. Adefuye; anthonio.adefuye@uct.ac.za

Received 26 January 2016; Revised 26 May 2016; Accepted 29 May 2016

Academic Editor: Jacek Tabarkiewicz

Copyright (C) 2016 Anthonio O. Adefuye et al. This is an open access article distributed under the Creative Commons Attribution License, which permits unrestricted use, distribution, and reproduction in any medium, provided the original work is properly cited.

Inflammation is a multifaceted process involving a host of resident and recruited immune cells that eliminate the insult or injury and initiate tissue repair. In the female reproductive tract (FMRT), inflammation-mediated alterations in epithelial, vascular, and immune functions are important components of complex physiological processes and many local and systemic pathologies. It is well established that intracoital and postcoital function of seminal fluid (SF) goes beyond nutritive support for the spermatozoa cells. SF, in particular, the inflammatory bioactive lipids, and prostaglandins present in vast quantities in SF, have a role in localized immune modulation and regulation of pathways that can exacerbate inflammation in the FMRT. In sexually active women SFmediated inflammation has been implicated in physiologic processes such as ovulation, implantation, and parturition while also enhancing tumorigenesis and susceptibility to infection. This review highlights the molecular mechanism by which SF regulates inflammatory pathways in the FMRT and how alterations in these pathways contribute to physiology and pathology of the female reproductive function. In addition, based on findings from TaqMan ${ }^{\circledR} 96-$ Well Plate Arrays, on neoplastic cervical cells treated with $\mathrm{SF}$, we discuss new findings on the role of SF as a potent driver of inflammatory and tumorigenic pathways in the cervix.

\section{Introduction}

Characteristically regarded as response to tissue injury or pathogenic insult, inflammation is a multifaceted process that involves a host of resident and recruited immune cell types working together to promote the elimination of insult or injury and initiate tissue repair [1].

In the female reproductive tract (FMRT), complex physiological processes such as menstruation, ovulation, parturition, and implantation have been shown to display hallmark of inflammation [1]. These reproductive events are associated with the upregulation of inflammatory mediators including cytokines, growth factors, and lipid mediators within the host [2]. Similarly, it is well recognized and widely accepted that inflammation-mediated alteration in epithelial, vascular, and immune functions within the female reproductive tract are important components of many local and systemic pathologies including cervical cancer, endometrial cancer, pelvic inflammatory disease, and HIV infection [3]. In addition to endogenous physiologic response, inflammation within the female genital tract can be mediated by a variety of exogenous effectors, including exposure to seminal fluid (SF) $[4,5]$.

It is well established that intracoital and postcoital function of SF goes beyond nutritive support for the spermatozoa cells. Consisting of a complex mixture of molecules including glycoproteins, cytokines, growth factors, and prostaglandins [6], SF can mount inflammatory responses in the female reproductive tract $[5,7]$. These SF-mediated inflammatory 
responses have been suggested to impact on both physiologic [8] and pathologic conditions within the FMRT. In this review, we discuss the molecular mechanism by which SF regulates inflammation and inflammatory pathways in the female reproductive tract and how alterations in these pathways contribute to physiology and pathology of the female reproductive function.

\section{Immune Response and Inflammation in the FMRT}

Inflammation is an integral part of the immune system response to infection or tissue injury [9]. Anatomical structures within the FMRT are divided into two distinct groups, namely, the sterile upper FMRT (the fallopian tubes, uterus, and endocervix) and the nonsterile lower FMRT (ectocervix and vagina) [10]. Consequent of its close proximity to the rectum, the lower FMRT is highly prone to secondary bacterial contamination [11] and as such requires an efficient immune system to protect the host from overwhelming infection.

Constituents of the innate immune system such as the pattern recognition toll-like receptors (TLRs), natural antimicrobial peptides (NAPs), defensins, and the complement system all work in synergy to protect the FMRT from exogenous threats [12]. TLRs are ubiquitously expressed in the endometrium, cervix, fallopian tubes, and epithelial cells [13]. TLRs recognize pathogen-associated molecular peptides, microbial-associated molecular peptides, and dangerassociated molecular peptides and respond by mediating increased cytokine and chemokine production leading to increased chemotaxis of monocytes and neutrophils into surrounding tissue.

NAPs including secretory leukocyte protease inhibitor (SLPI) and elafin are found in highest concentration within the cervical mucus and vagina, where they prevent host tissue damage by inhibiting proteases released by Gram-negative and Gram-positive bacteria $[10,12,14]$. Human defensins $(\alpha$ and $\beta$ ) are small cationic proteins that have antibacterial, antifungal, and antiviral properties important for host protection [10]. $\alpha$-defensins are found in neutrophils and epithelial surfaces as human neutrophil peptides 1-4 and human $\alpha$ defensins 5 and 6 , respectively, while $\beta$-defensins are found primarily on epithelial surfaces as human $\beta$-defensins (HBDs) 1-6 [10,14]. Defensins can be constitutively expressed or induced after inflammatory or infectious stimulus [10, 14]. The chemoattractant properties of $\beta$-defensins facilitate interaction between the innate and adaptive immune responses [14].

Cell-mediated immune responses protect the female from sexually transmitted intracellular disease causing agents. Immune cells are differentially distributed in each organ of the FMRT [15]. CD3 ${ }^{+} \mathrm{T}$ cells are distributed throughout the FMRT, while B cells are rare [15]. However, unlike the peripheral blood the FMRT consist of more $\mathrm{CD} 8^{+}$and less $\mathrm{CD} 4^{+}$ $\mathrm{T}$ cells [15]. In addition, antigen-presenting cells (APCs) found in the FMRT have been shown to constitutively express MHC (major histocompatibility complex) class II molecules [16].
However, while eliminating threatening sexually transmitted and environmental pathogens, the mucosal immune system of the FMRT is uniquely adapted to facilitate specialized physiological functions such as ovulation, menstruation, implantation, pregnancy, and parturition [10].

\section{Physiologic Inflammation and FMRT}

Physiologic inflammation is usually self-limiting because production of proinflammatory cytokines also gives way to anti-inflammatory cytokine secretion as the healing progresses [17]. In the female reproductive tract, injury and tissue remodeling orchestrated by physiological process such as ovulation, menstruation, implantation, and parturition triggers inflammatory cascade [1].

3.1. Ovulation. Ovulation is a complex physiologic process that involves series of biochemical and biophysical events that ultimately lead to the rupture of the preovulatory follicle and the release of the maternal germ cell [18]. Ovulatory process is initiated by luteinizing hormone (LH) surge [19]. This process displays all the hallmark of acute, physiologic (self-controlled) inflammatory reaction, including expression of inflammatory molecules (PGs, LTs, histamine, and cytokines), leukocyte extravasation, edema, hyperaemia, and induction of proteolytic and collagenolytic activities [20, 21]. Furthermore, the expression of innate immune cell-related surveillance proteins (toll-like receptors 2 and 4) by the ovarian granulosa cells and cumulus cells during ovulation thus suggest a role for the innate immune system in this process [22].

3.2. Menstruation. Menstruation results from partial breakdown of the functional layer of the endometrium accompanied by shedding of cell debris and uterine bleeding that occurs following the fall in progesterone level resulting from the demise of the corpus luteum at the end of a normal reproductive cycle [23]. Menstruation involves a complex series of events parallel to those of inflammatory response. Within the endometrial epithelial cells, progesterone withdrawal releases $\mathrm{NF}-\kappa \mathrm{B}$ from its inhibition by $\mathrm{I} \kappa \mathrm{B}$ leading to the induction of inflammatory gene, including COX-2, MMP-9, CXCL8, CCL5, Mn-SOD, CCL1, CCL3, IL-6, IL-1 $\beta$, CXCL1, GM-CSF, TNF- $\alpha$, and CXC chemokines resulting in an influx of inflammatory cells $[24,25]$. These proinflammatory mediators and inflammatory cells induce cascade of degradative enzymes, particularly matrix metalloproteinase in the endometrial epithelial cells, inducing both their production and activation leading to rapid breakdown of the extracellular matrix supporting the tissue.

3.3. Implantation. Embryo implantation starts with blastocyst apposition to the uterine endometrium, followed by its attachment to the endometrial surface epithelium [26]. This process bears a resemblance to "an open wound" requiring a strong inflammatory response [27]. The blastocyst breaks through the uterine epithelial lining to implant, thus creating an arena of invading, dying, and repairing cells [26]. Substantial amounts of proinflammatory Th1 cells and cytokines 
including TNF $\alpha$, IL-8, and IL-6 characterize early implantation $[28,29]$. In addition, elevated levels of PGs are found in areas of increased endometrial vascular permeability associated with initiation of implantation, suggesting that PGs play an important role during implantation [30]. These potent inflammatory mediators can be secreted by the endometrial cells themselves as well as by infiltrating immune cells recruited to the site of implantation [27]. Similarly, secretion of anti-inflammatory mediators such as IL-10 and adiponectin helps prevent excessive inflammation, suggesting that regulation of inflammation during implantation is a sequential event in which proinflammation is followed by anti-inflammation or both occurring in continual balance to attain physiologic state.

3.4. Parturition. Emerging evidence shows that normal parturition is characterized by massive influx of immune cells including neutrophils and macrophages into the myometrium and the cervix $[31,32]$. The invading leukocytes as well as the myometrium, cervix and foetal membranes collectively release proinflammatory mediators such as cytokines and PGs to promote myometrial contractility via the upregulation of TNF- $\alpha$ and IL- $1 \beta$ whose effect on the myometrium is similar to that of oxytocin, by inducing COX-2 expression and the production of $\mathrm{PGE}_{2}$ in the myometrial cells $[33,34]$. In addition, these mediators promote cervical ripening and membrane rupture via the activation of MMPs, cathepsin S, and COX-2 and inhibition of tissue inhibitor of metalloproteinase- (TIMP-) 2 [35-38].

\section{Inflammation and Pathology of FMRT}

Deregulation of any of the mediating factors in the inflammatory cascade can lead to abnormalities and ultimately pathogenesis.

4.1. Pelvic Inflammatory Disease (PID). PID is an inflammatory condition of the FMRT (cervix, uterus, fallopian tubes and adjacent pelvis structures) caused by sexually transmitted microorganism including Chlamydia trachomatis and Neisseria gonorrhea [39]. Infection of the epithelial cells by these microorganisms is characterized by secretion of proinflammatory cytokines responsible for disease progression [40, 41]. The innate immune system remains the first line of defense against pathogenic infection and relies on conserved family of pattern recognition receptors (PPRs) including toll-like receptor (TLR) family [42] for pathogen recognition [43, 44]. TLRs are expressed in the FMRT [44]. After binding to bacterial ligand, TLR signaling mediates the induction of proinflammatory cytokine and chemokine genes and priming of the adaptive immune system that leads to pathogen elimination [45]. However, increased or persistent TLR signaling can prolong the inflammatory response [46].

4.2. FMRT Cancers. The inverse association between the long-term use of NSAID and reduced risk of several cancers supports the link between inflammation and cancer [47, 48]. Similarly, several epidemiological studies have documented a positive relationship between local tissue inflammation and risk of cancer development [49]. Although the detailed molecular mechanism of inflammation-mediated cancer still remains elusive, it is established that proinflammatory cytokines such as TNF- $\alpha$ and IL-1 $\alpha$ produced by inflamed local tissue and infiltrating immune cells play a vital role [17] via the induction of rapid cell division and production of free radicals that subsequently cause DNA damage [50]. In the context of FMRT malignancies, inflammation can contribute to the initiation and progression of neoplastic conditions via the release of cytokines and growth factors to facilitate immune cell recruitment, cell proliferation, angiogenesis, and sustained tumor growth [1]. In the FMRT, ovarian, endometrial, and cervical cancer are the most common gynecological malignancy encountered [51].

Epithelial ovarian cancer (EOC) is a highly lethal gynecological cancer characterized by overall poor prognosis over the past few decades [52]. Although the genetic events within the neoplastic cells themselves are crucial for disease development, the most important hypothesis regarding EOC carcinogenesis remains the ovulation theory which relates the risk of cancer development to incessant ovulation [52, 53]. Indeed, the protective effect of oral contraceptives (OCs) has been subsequently reported in several studies [54]. The ovulatory process and repair steps following the release of the ovum is characterized by recruitment of immune cells to the wounded epithelial surface and secretions of enormous amount of cytokines, chemokines, PGs, bioactive eicosanoids, plasminogen activation factor, collagenases, and various growth factors [55], reminiscent of a proinflammatory network. Similarly, components of proinflammatory pathway signaling including ILs/cytokines, free radicals, NF- $\kappa$ B, STAT-3, iNOS, COX-2/PGs, and VEGF have been shown to promote EOC genesis, growth, and progression [56, 57]. COX-2 was found to be upregulated in nonmucinous ovarian cancers, and its expression was correlated with poorer prognosis [58]. Continual exposure of the ovarian surface epithelium (OSE) adjacent to the site of ovulation to this inflammatory and oxidative milieu results in an increased risk of neoplastic transformation. Consistent with these findings, it has been shown that patients with chronic NSAID use have a reduced risk of EOC [59].

Circumstantial evidence linking inflammation and endometrial neoplasia has been described [49]. Given the inflammatory components of menstruation as described earlier, these factors could bear on the initiation and progression of endometrial neoplasia [60]. Studies on endometrial tissue explant shows that NF- $\kappa$ B is overtly expressed in endometrial hyperplasia and endometrial carcinoma and notably decreased NF- $\kappa \mathrm{B}$ expression also coincides with an increase in apoptosis in low-grade cancer [61]. Besides its role as a major transcription factor for numerous proinflammatory genes, NF- $\kappa \mathrm{B}$ induces the expression of COX- 2 in endometrial carcinoma [62] where it enhances the production of $\mathrm{PGE}_{2}$ in both the malignant and adjacent endometrial stromal cells [63]. Within the neoplastic endometrium, elevated COX-2 and $\mathrm{PGE}_{2}$ can facilitate angiogenesis [64], increase cell proliferation, decrease apoptosis [65], and facilitate tissue invasion [66] leading to increased tumor aggressiveness. Several prospective cohort studies and in vitro experiments 
have shown that the use of aspirin is associated with reduced risk of endometrial cancer and inhibition of endometrial cancer cell growth [47] suggesting that endometrial cancer is inflammatory-dependent.

Cervical cancer is a chronic inflammatory disease and one of the leading causes of cancer-related death worldwide with a higher incidence rate reported in underdeveloped countries [67]. It is well established that persistent infection with high-risk HPV is crucial to disease pathogenesis [68]. However, only a subset of women infected with high-risk HPV will proceed to develop invasive cervical cancer, thus suggesting that other cofactors must be present for the development of malignancy [69]. Studies have reported an association between the level of cervical inflammation and the development of high grade cervical neoplasia [70] or invasive cervical cancer [71]. It has been reported that cervical inflammation but not the actual diagnosis of a specific sexually transmitted infection is associated with the development of squamous intraepithelial lesions within the cervix [72]. Direct links between increased proinflammatory cytokine levels in patients and increasing grade of cervical intraepithelial neoplasia and invasive cervical cancer have been established [73]. Similarly, proinflammatory COX-PGs axis has been shown to be elevated in cervical cancer [74].

\section{SF a Potent Inflammatory Mediator in the FMRT}

SF is a complex endogenous fluid comprising secretions of male accessory sexual glands (cowper's and littre glands, prostate, and the seminal vesicles) that provides nutritive support to the mammalian spermatozoa [75]. Secretions from each of these reproductive organs are biochemically distinct and, on mixing as occurs at ejaculation, give rise to the complex biochemical nature of the SF. Exposure of the FMRT to SF during coitus has been shown to elicit substantial changes in the leukocyte populations within the cervix, initiating a reaction reminiscent of inflammatory response with effects that penetrate through the stratified epithelial layer and deep into the stroma of the ectocervix [5]. This finding is supported by the lack of an observed inflammatory response in the absence of coitus or with condom-protected coitus [5]. After coitus, the degree at which SF normally activates the secretion of proinflammatory components in any compartment of the female reproductive tract is poorly understood. However, it has been established that influx of immune cells expands inducible regulatory $\mathrm{T}$ cell population, promoting immune tolerance there by preparing the reproductive tract for conception $[5,76,77]$.

5.1. SF PGE 2 Potent Proinflammatory Mediator in the FMRT. $\mathrm{SF}$ is known to contain an enormous diversity of antigenically distinct molecules [78]. However, it is the highly expressed levels of prostaglandins found in human SF [79] that have attracted much interest of late. Of the PGs present in SF, $\mathrm{PGE}_{2}$ has been identified as one of the predominant types detected $[80,81] . \mathrm{PGE}_{2}$ is a strong chemotactic agent for neutrophils [82]. Over the years, studies have shown that overt expression of $\mathrm{PGE}_{2}$ and its signaling is found in numerous disorders including cervical cancer $[83,84]$ and women infected with HIV and HPV $[85,86]$. It has been shown that $\mathrm{PGE}_{2}$ potentiates the chronic inflammatory response seen in these diseases, leading to greater tumorigenesis (cervical cancer) [84] and enhanced viral replication (HIV infection) [87]. Study by Joseph et al. identified $\mathrm{PGE}_{2}$ present abundantly in SF as the main constituent responsible for SF-mediated inflammatory effects in vaginal cells [88].

Recently, we identified SF-PGE 2 as the main constituent responsible for SF-mediated regulation of pleotropic proinflammatory cytokine and HIV chemokine coreceptor in normal and neoplastic cervix $[89,90]$.

\section{SF-Mediated Inflammation and Physiology of the FMRT}

6.1. SF and Ovulation. Since the ovulatory process has been likened to an inflammatory reaction which includes immune cell infiltration of the tissue of the Graafian follicles [21], it has been speculated that SF could mediate leukocyte trafficking from the uterus to the ovary and that migrating leukocytes can serve as vector in augmenting ovulation [82]. In mammals, studies have shown that SF advance the anticipated time of ovulation by significant number of hours [91]. Similarly, it has been shown that SF of certain mammals contain ovulation-inducing factors that induce a surge in circulating concentrations of LH and induced an ovulatory and luteotropic response [92].

Although the mechanism and route of signal transduction from the uterus to the ovary are unknown, it is believed that signaling pathways could involve locally induced cytokines such as GM-CSF and TNF- $\alpha$ secreted by uterine epithelial cells after SF stimulation [4].

Several in vitro and ex vivo studies have shown that TNF$\alpha$ can induce ovulation or trigger events leading to ovulation [93]. These mediators may reach the ovarian stroma and preovulatory follicles via the lymphatic ducts and a countercurrent transfer system from the uterine vein to the uteroovarian artery and bind to receptors expressed on the surface of the ovarian cells [82]. While the effects of SF on ovulation have not been documented in humans, it is plausible that it act in similar manner to enhance the ovulatory process.

6.2. SF, Implantation and Parturition. After fertilization, the survival of the semiallogeneic zygote depends on adaptations and immune tolerance in maternal innate and adaptive immune system [94]. This tolerance is mediated in part by a unique subpopulation of $\mathrm{T}$ cells, regulatory $\mathrm{T}$ (Tregs) cells [95]. Tregs control immunologic self-tolerance by suppressing the generation of effector T cells (Teff) via an indoleamine-2,3-dioxygenase regulated pathway [96]. Robertson et al. demonstrated that exposure to SF at mating in mice promotes a state of immune tolerance to paternal alloantigens that may facilitate maternal acceptance of the conceptus at implantation, and the effects of SF are likely to be mediated by expansion of the Tregs cell pool [76]. It is well established that SF contains potent immune-regulatory molecules including TGF $\beta$ and PGE-related prostaglandins, particularly $19 \mathrm{OH}-\mathrm{PGE}_{1}$ and $19 \mathrm{OH}-\mathrm{PGE}_{2}$ [76]. These molecules 
facilitate the unique Tregs cell-inducing properties of SF by inducing nave $\mathrm{CD} 4^{+} \mathrm{CD} 25^{-} \mathrm{T}$ cells to differentiate into suppressor T cells expressing Foxp3 [97, 98]; these molecules facilitate the unique Tregs cell-inducing properties of SF. These findings suggest a role for SF in regulating maternal immune tolerance, a key factor required for successful implantation.

The role of coitus in cervical ripening and induction of labour has been extensively reviewed in [99]. It was suggested that coitus may stimulate cervical ripening and the onset of labour in part by the direct action of PGs present in SF [99]. However, there is insufficient data at present to confirm these findings.

\section{SF-Mediated Inflammation and Pathology of the FMRT}

7.1. SF Hypersensitivity (Seminal Plasma Hypersensitivity). As discussed earlier, the human SF contains diverse range of antigenically distinct molecules including the prostatespecific antigen (PSA), a 33-34 kDa glycoprotein with serineprotease activity $[14,100,101]$. Exposure of the FMRT to this SF-derived glycoprotein has been the main aetiological factor implicated in SF hypersensitivity [101]. SF hypersensitivity is an IgE mediated type I hypersensitivity reaction characterized by a spectrum of clinical symptoms manifesting as either systemic and/or localized reactions after exposure to specific protein components in SF [5]. However, unlike typical allergic reactions SF hypersensitivity rarely has a heritable/familial component [102]. It has been postulated that SF proteases such as PSA can cause degradation of vagina mucosal tight junctions, leading to the activation of protease activated receptor- (PAR-) 2 on the vagina epithelial cells and release of proinflammatory cytokines and localized inflammation [101]. In addition, $\mathrm{SF}_{-} \mathrm{PGE}_{2}$ has been implicated in the pathophysiology of localized SF hypersensitivity. This is supported by findings by Ghosh and Bernstein, wherein women with localized SF hypersensitivity experience attenuation of their symptoms following ingestion of nonsteroidal anti-inflammatory agent prior to unprotected intercourse [101]. This pathophysiology is consistent with histopathological findings that reveal a localized nonspecific inflammation and inconsistent with a typical allergic IgE-mediated reaction [103]. However, further investigation of the mechanism(s) related to localized SF hypersensitivity is warranted.

7.2. SF and Endometrial Tumorigenesis. Emerging evidence suggests that constituents of SF can travel into the endometrium and regulate gene expression [104]. Thus, suggesting that, in sexually active women, endometrial pathologies may be enhanced following exposure to SF [105]. This was confirmed in a study by Sales et al. where SF was shown to modulate neoplastic endometrial cell function. Sales and colleagues demonstrated that SF, acting via EP2-EGFR-ERK signal pathways upregulated the expression of the potent mitogenic/proangiogenic gene, fibroblast growth factor 2 (FGF2), in the neoplastic endometrium [106].
7.3. SF and Cervical Tumorigenesis. Central to the role of SF in augmenting cervical tumorigenesis is its ability to regulate the inflammatory processes in the cancer milieu. Lipid components of SF can be reabsorbed into the vaginal fornix or local tissues [107], where they can regulate tissue remodeling processes in an autocrine or paracrine manner [5]. We and others have demonstrated the proinflammatory role of SF on neoplastic cervical epithelium. These studies reveal that SF can promote cancer cell proliferation by inducing the expression of angiogenic genes and pleotropic proinflammatory cytokines/chemokines via the activation of pathways including COX-PGs, EGFR-ERK 1/2, NF- $\kappa$ B, and EP2-EGFRPI3kinase-AKT pathways [89, 108-110]. Discovery of these pathways suggests that SF can regulate a wide range of inflammatory pathways to augment cervical tumorigenesis. Hence, with the aim of investigating gene arrays of inflammatory pathways that can be regulated by SF in neoplastic cervical epithelial cells, cervical adenocarcinoma cells (HeLa) were treated with serum-free media containing SF at a dilution of 1:50 or serum-free media with PBS (control) for $8 \mathrm{hrs}$ ( $n=5$ individual experiment done in duplicate). The 5 individual experiments were pooled together, RNA extracted, and the synthesized cDNA subjected to Real-Time RTPCR using TaqMan Plate Array (Human inflammation and human chemokines) (Applied Biosystems, USA) [90] on a Bio-Rad CFX96 ${ }^{\mathrm{TM}}$ quantitative RT-PCR system. Relative expression was calculated using the comparative $C_{t}$ method and arrays were normalized for RNA loading using 18s ribosomal RNA, glyceraldehyde-3-phosphate dehydrogenase (GAPDH), hypoxanthine phosphoribosyltransferase 1 (HPRT1), and glucuronidase beta (GUSB) as internal controls. In a separate experiment, validation of the TaqMan 96 array assay was done by comparing mRNA expression of selected genes (IL-1 $\alpha$, IL-8, IL-12 $\alpha$, PTGIR, PTGFR, and CXCR4) in HeLa S3 cells treated with SF (1:50) or PBS (control) for 4, 8, 16, and 24 hrs, respectively, and Real-Time RT-PCR done using SYBR Green on an $\mathrm{Eco}^{\mathrm{TM}}$ Real-Time PCR system (Illumina ${ }^{\mathrm{TM}}$ ).

We found that SF regulates components of eicosanoid signaling (cyclooxygenase and lipoxygenase), kallikrein-kininbradykinin receptor signaling, toll-like receptor-2 (TLR2) signaling and chemokine/cytokine signaling in neoplastic cervical epithelial cells (unpublished data) (Tables 1, 2, and 3).

Eicosanoids, including prostaglandins and leukotrienes, are biologically active lipids that have extensively been implicated in inflammation and cancer [111]. COX-1 expression has been shown to be upregulated in numerous human neoplasia [112]. SF-mediated regulation of COX-1 (2.43-fold induction) in the array is in agreement with a similar study by Sutherland et al. [110]. A major metabolite of COX enzyme is $\mathrm{PGE}_{2}$. $\mathrm{PGE}_{2}$ biosynthesis and signaling are significantly elevated in cervical cancer where it modulates tumor cell proliferation, differentiation, and apoptosis [109, 110, 113]. Hence, in sexually active women exposure to SF can lead to the activation of the COX-PGs signaling pathway consequent of COX-1 induction. Activated COX-PGs pathway can then promote $\mathrm{PGE}_{2}$-EP signaling, which can act in similar manner to enhance cervical inflammation and tumorigenesis. 
TABLE 1: Components of eicosanoid signalling regulated by SF in the Taqman 96-well plate array. Results are expressed as fold above control.

\begin{tabular}{lcc}
\hline Gene & Accession number & Fold change \\
\hline PTGS1 & NM_000962 & $2.43 \uparrow$ \\
LTC4S & NM_000897 & $10.03 \uparrow$ \\
PLA2G2A & NM_000300 & $3.00 \uparrow$ \\
PLCB4 & NM_000933 & $2.82 \uparrow$ \\
PLCG1 & NM_182811 & $2.90 \uparrow$ \\
PLCE1 & NM_016341 & $6.71 \uparrow$ \\
ANXA1 & NM_000700 & $6.66 \downarrow$ \\
ANXA3 & NM_005139 & $3.44 \downarrow$ \\
ANXA5 & NM_001154 & $>100 \downarrow$ \\
HPGD & NM_000860 & $3.12 \downarrow$ \\
\hline
\end{tabular}

$\uparrow$ : fold increase.

$\downarrow$ : fold decrease.

TABLE 2: Kallikrein-related peptidases regulated by SF in the Taqman 96-well plate array. Results are expressed as fold above control.

\begin{tabular}{lcc}
\hline Gene & Accession number & Fold change \\
\hline$K L K 1$ & NM_002257 & $1.56 \downarrow$ \\
$K L K 2$ & NM_001002231 & $19.59 \uparrow$ \\
$K L K 3$ & NM_001030047 & $3.45 \uparrow$ \\
$K L K 14$ & NM_022046 & $2.53 \uparrow$ \\
$K L K B 1$ & NM_000892 & $1.73 \uparrow$ \\
\hline
\end{tabular}

$\uparrow$ : fold increase.

$\downarrow$ : fold decrease.

In addition, SF-mediated regulation of COX-1 enzyme has recently been implicated in the upregulation of CCR5, an HIV chemokine coreceptor in the cervix [90]. Increase in HIV susceptibility can then further potentiate cervical tumorigenesis.

Similarly, it was observed that SF could also potentially regulate inflammation and tumor progression by inhibiting negative feedback regulators or inhibitory/anti-inflammatory pathways. The release of AA by phospholipase $A_{2}$ is negatively regulated by annexin (encoded by ANXA 1-5), a group of cellular proteins known to inhibit $\mathrm{CPLA}_{2}$ activity [114]. The gene array showed that SF inhibited annexin 1, 3, and 5 expressions by 6.66-fold, 3.44-fold, and $>100$-fold reduction, respectively (Table 1 ). By inhibiting annexin expression and upregulating phospholipase $\mathrm{A}_{2}$ (3-fold induction) expression (Table 1), SF ensures steady and continuous release of AA metabolite into the cascade for $\mathrm{PGH}_{2}$ synthesis, thereby driving inflammatory pathways and potentially enhancing tumor progression, by enhancing biosynthesis of $\mathrm{PGE}_{2}, \mathrm{PGF}_{2 \alpha}$, and $\mathrm{PGI}_{2}[111,115,116]$.

Furthermore, in addition to $\mathrm{PGE}_{2}$ production, inhibition of pathways that metabolize $\mathrm{PGE}_{2}$ can also prolong inflammation by enhancing ligand receptor interaction. $\mathrm{PGE}_{2}$ is metabolized through oxidation of its 15(S)-hydroxyl group by $\mathrm{NAD}^{+}$-linked 15-hydroxyprostaglandin dehydrogenase (15PGDH, encoded by HPGD) to inactive 15-keto products [117119]. 15-PGDH is a cytosolic enzyme that has been reported
TABLE 3: Proinflammatory cytokines/chemokines regulated by SF in the Taqman 96-well plate array. Results are expressed as fold above control.

\begin{tabular}{lcc}
\hline Gene & Accession number & Fold change \\
\hline CCL2 & NM_002982 & $4.43 \uparrow$ \\
CCL5 & NM_002985 & $5.24 \uparrow$ \\
CXCL1 & NM_001511 & $12.37 \uparrow$ \\
CXCL2 & NM_002089 & $2.04 \downarrow$ \\
CXCL3 & NM_002090 & $8.19 \uparrow$ \\
CXCL11 & NM_005409 & $2.47 \uparrow$ \\
IL1A & NM_000575 & $68.56 \uparrow$ \\
IL6 & NM_000600 & $4.19 \uparrow$ \\
IL8 & NM_000584 & $38.9 \uparrow$ \\
IL12A & NM_000882 & $2.36 \uparrow$ \\
IL13 & NM_002188 & $1.39 \uparrow$ \\
IL18 & NM_001562 & $17.84 \uparrow$ \\
MYD88 & NM_002468 & $9.41 \uparrow$ \\
NFKB1 & NM_001165412 & $2.32 \uparrow$ \\
SOCS5 & NM_014011 & $>100 \downarrow$ \\
TNF & NM_000594 & $26.55 \uparrow$ \\
TLR2 & NM_003264 & $88.47 \uparrow$ \\
TLR4 & NM_138554 & $1.66 \uparrow$ \\
ICAM1 & NM_000201 & $3.82 \uparrow$ \\
ITGAM & NM_000632 & $4.78 \uparrow$ \\
\hline Ifol & &
\end{tabular}

$\uparrow$ : fold increase.

$\downarrow$ : fold decrease.

to act as bladder, breast, gastric, lung, and colorectal tumor suppressor [120-125]. In immunodeficient mice, 15-PGDH inhibits the development of murine intestinal neoplasia $[125,126]$. These findings supported with the fact that 15PGDH expression is abolished in various cancers [118, 127], emphasizing the oncogenic potential of the PG biosynthesis pathway. In the array, SF suppressed HPGD expression (3.12fold inhibition) (Table 1). This can lead to reduction in $\mathrm{PGE}_{2}$ degradation and increased steady state levels of $\mathrm{PGE}_{2}$ resulting in enhanced cervical tumorigenesis.

Leukotrienes are powerful lipid mediators of inflammation in various acute and chronic inflammatory diseases [128, 129]. Compared with PGs, much less is known about the role of proinflammatory leukotrienes in cancer [111]. However, emerging data suggest that leukotrienes can play vital roles in carcinogenesis [111]. Data from the gene array shows that SF induces the expression of leukotriene $\mathrm{C}_{4}$ synthase $\left(\mathrm{LTC}_{4} \mathrm{~S}\right)$ (10-fold induction) (Table 1 ), an enzyme that catalyzes the conjugation of leukotriene $\mathrm{A}_{4}\left(\mathrm{LTA}_{4}\right)$ to form leukotriene $\mathrm{C}_{4}$ $\left(\mathrm{LTC}_{4}\right)$, the parent compound of the cysteinyl leukotrienes (CysLTs) ( $\mathrm{LTC}_{4}, \mathrm{LTD}_{4}$, and $\mathrm{LTE}_{4}$ ) [130]. CysLTs exert their biological activity by binding to two distinct CysLTs receptor (CysLT1 and CysLT2) [131, 132], with higher binding affinity to CysLT1 than CysLT2 [111]. CysLTs-CysLT1 signaling has been suggested to play an important role in carcinogenesis. In human colorectal and prostate cancer, CysLTs-CysLT1 signaling has been shown to mediate proliferation and inhibit apoptosis, thus conferring poor prognosis $[133,134]$. It is likely that CysLTs-CysLT1 signaling could regulate cervical cancer 
via similar mechanisms. Taken together, these findings suggests that SF can potentially enhance cervical tumorigenesis by not only directly enhancing proinflammatory and protumorigenic lipid signaling pathway $\left(\mathrm{COX}-\mathrm{PGE}_{2}\right.$ and $\mathrm{LTC}_{4} \mathrm{~S}-$ CysLTs,) but also indirectly concomitantly inhibiting the expression of enzyme systems that metabolize ligands of these pathways (HPGD), thereby driving inflammation forward.

Kallikrein-related peptidases (KLKs) belong to a subgroup of secreted serine proteases [135] that catalyzes several physiological processes within the human body [136]. SF induces the expression of several KLKs (KLK 2, 3, 14, and B1) and only marginally reduces the expression of KLK1 by 1.56fold reduction as seen in the gene array (Table 2). Emerging evidences designate a possible role for KLKs in inflammation and various cancer processes [136]. KLKs have been shown to mediate cancer cell proliferation and tumor growth mainly via insulin-like growth factors (IGFs) [135]. Activation of KLKs by inflammatory stimuli such as PGs in SF can result in the generation of biologically active kinins by limited proteolysis of kininogens $[137,138]$. Bradykinins are a group of pluripotent peptides implicated in various pathophysiological events [139]. This suggests that continuous exposure of cervical epithelial cells to SF can activate KLKs-kininBDKR1 signaling pathways to mediate chronic inflammatory reactions and augment tumor progression within the cervix.

Toll-like receptor- (TLR2-) 2 belongs to the family of type I transmembrane receptors structurally characterized by extracellular leucine rich repeats (LRRs) and an intracellular toll/IL-1 receptor (TIR) signaling domain [140]. TLR2 is activated by a wide range of pathogen-associated molecular patterns (PAMPs) including lipoproteins and bacterial lipopolysaccharides (LPS) [141]. Hence, it is very feasible that SF-induced TLR2 (88-fold induction) can be activated by lipoproteins that might be present within SF. Activated TLR2 can then recruit SF-induced MyD88 (9.41-fold induction) and NF- $\kappa \mathrm{B}$ (2.32-fold induction) (Table 3 ) to activate the TLR2MyD88-NF- $\kappa$ B signaling pathway. Translocated NF- $\kappa$ B can then mediate the release of proinflammatory and tumorigenic genes from the neoplastic cells themselves to augment cervical tumorigenesis. Consistent with this, Xie et al. showed that the activation of TLR2 in breast cancer cells significantly promote cellular invasion via the activation of NF- $\kappa \mathrm{B}$ [142]. Furthermore, in sexually active women, STIs such as gonorrhea are known cause of chronic cervicitis, a persistent inflammation of the cervix, which has been linked to cervical cancer $[143,144]$. It is plausible that the bacterial LPS present within infective SF can bind to the induced TLR2 to activate the TLR2-MyD88-NF- $\kappa$ B signaling pathway, releasing proinflammatory modulators to mediate cervical inflammation.

Recently chemokines and their receptors have been identified as key mediators of chronic inflammation, which play an important role in the pathogenesis and progression of various human cancers including cancer of the cervix [145148]. SF regulated the expression of chemokines CCL2, CCL5, CXCL1, CXCL2, CXCL3, CXCL8 (IL-8), and CXCL11 (Table 3) all of which play vital role in cervical cancer inflammation and tumorigenesis.

CCL2 (MCP-1) and RANTES (CCL5) are major determinants of macrophage and lymphocyte infiltration [149].
Hence, SF-mediated induction of CCL2 (MCP-1) and CCL5 (RANTES) (4.43- and 5.24-fold induction, resp.) (Table 3) suggests a role for both MCP-1 and RANTES in the characteristic postcoital inflammatory response described by Sharkey et al. [5]. The SF-mediated induction of CCL2 and CCL5 (4.43- and 5.24-fold induction) is in agreement with similar findings by Chen et al. wherein SF was shown to induce the expression of CCL2 and CCL5 in endometrial epithelial cells in vitro [150]. In addition, Schjenken et al. showed that SF mediated a 3.06-fold induction of CCL2 in the endometrium of CBAF1 female rats 8 hours after mating with an intact $\mathrm{Balb} / \mathrm{c}$ male rat [151]. CCL2 and CCL5 have been shown to modulate cell migration, invasion, and metastasis in several cancer cells [152]. It is likely that SF-induced CCL2 and CCL5 can act in similar manner to enhance cervical cancer cell migration, invasion, and metastasis.

Induction of CXCL1 (12.37-fold induction) and CXCL8 (38.9-fold induction) by SF as seen herein is in agreement with a similar study by Sales et al., where it was shown that SF induces the expression of CXCL1 and CXCL8 in HeLa cells and regulates vascular function in vitro [113]. Likewise, Chen and colleagues showed that SF mediated 6.5-fold and 14.4-fold induction of CXCL1 and CXCL8, respectively, in endometrial stromal fibroblast cells in vitro [150]. Furthermore, Wang et al. showed that $\mathrm{PGE}_{2}$ induces the expression of CXCL1 in human colorectal cancer cells and that expressed CXCL1 then induces microvascular endothelial cell migration and tube formation in vitro [153]. It is therefore very probable that the copious $\mathrm{PGE}_{2}$ found in SF [80] can mediate CXCL1 induction in neoplastic cervical cancer cells. Thus, suggesting that exposure of neoplastic cervical epithelium to SF can lead to increased tumor angiogenesis and invasiveness/metastasis consequent of CXCL1 and IL-8 expression.

Similarly, findings from the array showed that SF regulates the expression of pleotropic proinflammatory cytokines IL- $1 \alpha$, TNF, and IL- 6 and components of their respective signaling cascade in neoplastic epithelial cells (Table 3). This is in agreement with a study by Adefuye et al. where it was shown that SF induced the expression of IL- $1 \alpha$ in both normal and neoplastic cervix via EP2-EGFR-PI3kinase-AKT signaling [3]. Furthermore, Castrilli et al. reported that IL-1 $\alpha$ promotes the growth of both normal and neoplastic human cervical epithelial cells in vitro [154], thus suggesting a similar role for IL- $1 \alpha$ in vivo. SF induction of IL-6 is in keeping with similar study by Sutherland et al. [110]. SF-mediated downregulation of suppressor of cytokine signaling- (SOCS-) 5 (Table 3) suggests that SF augments proinflammatory cytokine signaling within the cervical cancer microenvironment to enhance disease progression.

Induction of immune modulatory cytokines IL-12 $\alpha$ and IL-18 by SF (Table 3) suggests a role for SF in the regulation of cervical immune response. IL-12 $\alpha$ and IL-18 are proinflammatory cytokines $[155,156]$ capable of inducing the production of interferon- $\gamma$ (IFN- $\gamma$ ) [157] and cell-mediated immunity which are important factors in determining the progression of HPV related cervical lesion including cervical cancer [158]. Furthermore, the observed SF induction of cell adhesion molecules ICAM1 (3.82-fold induction) and ITGAM1 


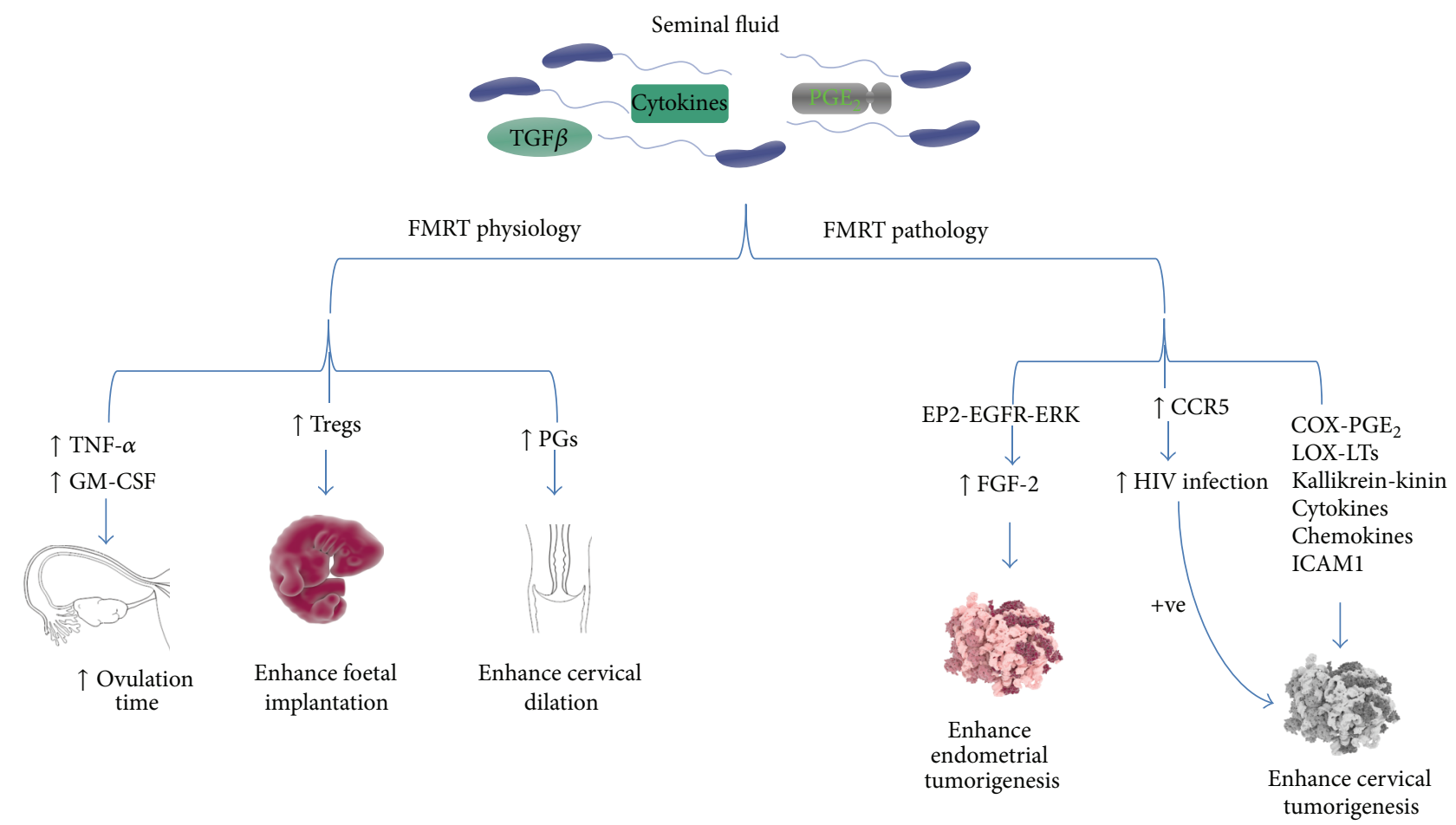

FIGURE 1: Schematic diagram showing the role of seminal fluid-mediated inflammation in the regulation of physiology and pathology of the female reproductive tract. SF has been shown to contain a wide variety of signaling molecules including cytokines, TGF $\beta$, and PGE 2 . Exposures of the female reproductive tract (FMRT) to these molecules can impact on the physiology and pathology of the FMRT. SF regulation of TNF- $\alpha$ and GM-CSF enhances ovulation process by increasing ovulation time. Regulation of Tregs population promotes maternal tolerance and foetal implantation while SF-mediated regulation of PGs enhances cervical dilation during parturition. It has been established that SF can mediate pathologic conditions within the FMRT. In endometrial tumorigenesis, SF-mediated regulation of FGF-2 via the activation of EP2-EGFR-ERK signaling enhances tumor progression. Similarly, by regulating COX-PGE 2 , LOX-LTs, kallikrein-kinin, cytokines, and chemokine signaling SF promotes cervical tumorigenesis in sexually active women. In addition, SF-mediated regulation of CCR5 (HIV chemokine coreceptor) further allude to its role in HIV infection and cervical tumorigenesis.

(4.78-fold induction) (Table 3) suggest that SF can also play a role in cervical cancer cell metastasis [159].

Taken together, regulation of these inflammatory pathways suggests that SF can play a critical role in cervical inflammation and consequently neoplastic transformation in the FMRT.

\section{Conclusion}

There is burgeoning body of in vivo and in vitro evidence for the involvement of SF-mediated inflammation in normal and pathophysiologic processes in the FMRT. SF has been shown to contain a wide variety of signaling molecules including cytokines, TGF $\beta$, and $\mathrm{PGE}_{2}$. Exposures of the female reproductive tract (FMRT) to these molecules can impact on the physiology and pathology of the FMRT. Differential expression of pleiotropic inflammatory cytokine genes as demonstrated by the TaqMan Plate Array data further gives credence to the fundamental role played by inflammatory mediators present in SF in regulating various pathways involved in physiologic and pathologic processes of the FMRT. These findings suggest that SF can potentially regulate the induction of inflammatory pathways in neoplastic cervix. Regulation of these inflammatory pathways plays a critical role in cancer cell angiogenesis, proliferation, invasion, metastasis, and survival. Overall, it is evident that the inflammatory response initiated by SF would impact on all physiological and pathophysiological events within the FMRT. As demonstrated schematically in Figure 1 and detailed in the figure legend, SF impact on normal physiology of the FMRT is on ovulation, implantation, and parturition. The pathological impact of SF is on promoting endometrial and cervical tumor growth and, in addition, increasing susceptibility to HIV infection. However, further research is clearly needed to elucidate in detail the mechanistic role of SF in FMRT physiology and pathology.

\section{Competing Interests}

The authors declare that there is no conflict of interests regarding the publication of this paper.

\section{Acknowledgments}

This research was funded by the South African MRC and Cancer SA. Anthonio O. Adefuye was supported by grant funding from National Research Foundation of South Africa (NRF) and University of Cape Town Research Committee 
(URC). The funders played no role in the design or interpretation of the paper or the decision to publish.

\section{References}

[1] H. N. Jabbour, K. J. Sales, R. D. Catalano, and J. E. Norman, "Inflammatory pathways in female reproductive health and disease," Reproduction, vol. 138, no. 6, pp. 903-919, 2009.

[2] C. N. Serhan, N. Chiang, and T. E. Van Dyke, "Resolving inflammation: dual anti-inflammatory and pro-resolution lipid mediators," Nature Reviews Immunology, vol. 8, no. 5, pp. 349-361, 2008.

[3] A. Adefuye, A. A. Katz, and K. J. Sales, "The regulation of inflammatory pathways and infectious disease of the cervix by seminal fluid," Pathology Research International, vol. 2014, Article ID 748740, 9 pages, 2014.

[4] S. O’Leary, M. J. Jasper, G. M. Warnes, D. T. Armstrong, and S. A. Robertson, "Seminal plasma regulates endometrial cytokine expression, leukocyte recruitment and embryo development in the pig," Reproduction, vol. 128, no. 2, pp. 237-247, 2004.

[5] D. J. Sharkey, K. P. Tremellen, M. J. Jasper, K. GemzellDanielsson, and S. A. Robertson, "Seminal fluid induces leukocyte recruitment and cytokine and chemokine mRNA expression in the human cervix after coitus," Journal of Immunology, vol. 188, no. 5, pp. 2445-2454, 2012.

[6] M. Maegawa, M. Kamada, M. Irahara et al., "A repertoire of cytokines in human seminal plasma," Journal of Reproductive Immunology, vol. 54, no. 1-2, pp. 33-42, 2002.

[7] D. J. Sharkey, A. M. Macpherson, K. P. Tremellen, and S. A. Robertson, "Seminal plasma differentially regulates inflammatory cytokine gene expression in human cervical and vaginal epithelial cells," Molecular Human Reproduction, vol. 13, no. 7, pp. 491-501, 2007.

[8] J. E. Schjenken and S. A. Robertson, "Seminal fluid and immune adaptation for pregnancy-comparative biology in mammalian species," Reproduction in Domestic Animals, vol. 49, pp. 27-36, 2014.

[9] K. Newton and V. M. Dixit, "Signaling in innate immunity and inflammation," Cold Spring Harbor Perspectives in Biology, vol. 4, no. 3, 2012

[10] A. W. Horne, S. J. Stock, and A. E. King, "Innate immunity and disorders of the female reproductive tract," Reproduction, vol. 135, no. 6, pp. 739-749, 2008.

[11] M. Johansson and N. Y. Lycke, "Immunology of the human genital tract," Current Opinion in Infectious Diseases, vol. 16, no. 1, pp. 43-49, 2003.

[12] A. E. King, H. O. D. Critchley, and R. W. Kelly, "Innate immune defences in the human endometrium," Reproductive Biology and Endocrinology, vol. 1, article 116, 2003.

[13] K. Nasu and H. Narahara, "Pattern recognition via the toll-like receptor system in the human female genital tract," Mediators of Inflammation, vol. 2010, Article ID 976024, 12 pages, 2010.

[14] J. A. Bernstein, "Immunologic disorders of the female and male reproductive tract," Annals of Allergy, Asthma and Immunology, vol. 108, no. 6, pp. 390-395, 2012.

[15] S. K. Lee, C. J. Kim, D.-J. Kim, and J.-H. Kang, "Immune cells in the female reproductive tract," Immune Network, vol. 15, no. 1, pp. 16-26, 2015.

[16] N. Iijima, J. M. Thompson, and A. Iwasaki, "Dendritic cells and macrophages in the genitourinary tract," Mucosal Immunology, vol. 1, no. 6, pp. 451-459, 2008.
[17] M. Philip, D. A. Rowley, and H. Schreiber, "Inflammation as a tumor promoter in cancer induction," Seminars in Cancer Biology, vol. 14, no. 6, pp. 433-439, 2004.

[18] J. Sirois, K. Sayasith, K. A. Brown, A. E. Stock, N. Bouchard, and M. Doré, "Cyclooxygenase-2 and its role in ovulation: a 2004 account," Human Reproduction Update, vol. 10, no. 5, pp. 373385, 2004.

[19] J. S. Richards, D. L. Russell, S. Ochsner, and L. L. Espey, “Ovulation: new dimensions and new regulators of the inflammatorylike response," Annual Review of Physiology, vol. 64, pp. 69-92, 2002.

[20] L. L. Espey, "Ovulation as an inflammatory reaction: a hypothesis," Biology of Reproduction, vol. 22, no. 1, pp. 73-106, 1980.

[21] L. L. Espey, "Current status of the hypothesis that mammalian ovulation is comparable to an inflammatory reaction," Biology of Reproduction, vol. 50, no. 2, pp. 233-238, 1994.

[22] J. S. Richards, Z. Liu, and M. Shimada, "Immune-like mechanisms in ovulation," Trends in Endocrinology and Metabolism, vol. 19, no. 6, pp. 191-196, 2008.

[23] J. Evans and L. A. Salamonsen, "Inflammation, leukocytes and menstruation," Reviews in Endocrine and Metabolic Disorders, vol. 13, no. 4, pp. 277-288, 2012.

[24] J.-J. Zhang, Z.-M. Xu, C.-M. Zhang et al., "Pyrrolidine dithiocarbamate inhibits nuclear factor- $\kappa \mathrm{B}$ pathway activation, and regulates adhesion, migration, invasion and apoptosis of endometriotic stromal cells," Molecular Human Reproduction, vol. 17, no. 3, pp. 175-181, 2011.

[25] D. B. Hardy, B. A. Janowski, D. R. Corey, and C. R. Mendelson, "Progesterone receptor plays a major antiinflammatory role in human myometrial cells by antagonism of nuclear factor- $\kappa \mathrm{B}$ activation of cyclooxygenase 2 expression," Molecular Endocrinology, vol. 20, no. 11, pp. 2724-2733, 2006.

[26] N. Dekel, Y. Gnainsky, I. Granot, and G. Mor, "Inflammation and implantation," American Journal of Reproductive Immunology, vol. 63, no. 1, pp. 17-21, 2010.

[27] G. Mor, I. Cardenas, V. Abrahams, and S. Guller, "Inflammation and pregnancy: the role of the immune system at the implantation site," Annals of the New York Academy of Sciences, vol. 1221, no. 1, pp. 80-87, 2011.

[28] M. J. Jasper, A. S. Care, B. Sullivan, W. V. Ingman, J. D. Aplin, and S. A. Robertson, "Macrophage-derived LIF and IL1B regulate alpha(1,2)fucosyltransferase 2 (Fut2) expression in mouse uterine epithelial cells during early pregnancy," Biology of Reproduction, vol. 84, no. 1, pp. 179-188, 2011.

[29] K. Yoshinaga, "Review of factors essential for blastocyst implantation for their modulating effects on the maternal immune system," Seminars in Cell and Developmental Biology, vol. 19, no. 2, pp. 161-169, 2008.

[30] T. G. Kennedy, C. Gillio-Meina, and S. H. Phang, "Prostaglandins and the initiation of blastocyst implantation and decidualization," Reproduction, vol. 134, no. 5, pp. 635-643, 2007.

[31] R. Romero, J. Espinoza, L. F. Gonçalves, J. P. Kusanovic, L. A. Friel, and J. K. Nien, "Inflammation in preterm and term labour and delivery," Seminars in Fetal and Neonatal Medicine, vol. 11, no. 5, pp. 317-326, 2006.

[32] I. Osman, A. Young, M. A. Ledingham et al., "Leukocyte density and pro-inflammatory cytokine expression in human fetal membranes, decidua, cervix and myometrium before and during labour at term," Molecular Human Reproduction, vol. 9, no. 1, pp. 41-45, 2003. 
[33] D. M. Slater, W. J. B. Dennes, J. S. Campa, L. Poston, and P. R. Bennett, "Expression of cyclo-oxygenase types-1 and -2 in human myometrium throughout pregnancy," Molecular Human Reproduction, vol. 5, no. 9, pp. 880-884, 1999.

[34] J. Zuo, Z. M. Lei, C. V. Rao, M. Pietrantoni, and V. D. Cook, "Differential cyclooxygenase-1 and -2 gene expression in human myometria from preterm and term deliveries," Journal of Clinical Endocrinology and Metabolism, vol. 79, no. 3, pp. 894-899, 1994.

[35] A. E. King, R. W. Kelly, J.-M. Sallenave, A. D. Bocking, and J. R. G. Challis, "Innate immune defences in the human uterus during pregnancy," Placenta, vol. 28, no. 11-12, pp. 1099-1106, 2007.

[36] M. B. Sennström, G. Ekman, G. Westergren-Thorsson et al., "Human cervical ripening, an inflammatory process mediated by cytokines," Molecular Human Reproduction, vol. 6, no. 4, pp. 375-381, 2000.

[37] P. Xu, N. Alfaidy, and J. R. G. Challis, "Expression of matrix metalloproteinase (MMP)-2 and MMP-9 in human placenta and fetal membranes in relation to preterm and term labor," Journal of Clinical Endocrinology and Metabolism, vol. 87, no. 3, pp. 1353-1361, 2002.

[38] S. C. Riley, R. Leask, F. C. Denison, K. Wisely, A. A. Calder, and D. C. Howe, "Secretion of tissue inhibitors of matrix metalloproteinases by human fetal membranes, decidua and placenta at parturition," Journal of Endocrinology, vol. 162, no. 3, pp. 351359, 1999.

[39] D. E. Soper, "Pelvic inflammatory disease," Obstetrics \& Gynecology, vol. 116, no. 2, pp. 419-428, 2010.

[40] S. Dessus-Babus, T. L. Darville, F. P. Cuozzo, K. Ferguson, and P. B. Wyrick, "Differences in innate immune responses (in vitro) to HeLa cells infected with nondisseminating serovar E and disseminating serovar L2 of Chlamydia trachomatis," Infection and Immunity, vol. 70, no. 6, pp. 3234-3248, 2002.

[41] R. M. Johnson, "Murine oviduct epithelial cell cytokine responses to Chlamydia muridarum infection include interleukin-12-p70 secretion," Infection and Immunity, vol. 72, no. 7, pp. 3951-3960, 2004.

[42] C. Sonnex, "Toll-like receptors and genital tract infection," International Journal of STD and AIDS, vol. 21, no. 3, pp. 153$157,2010$.

[43] H. Kanzler, F. J. Barrat, E. M. Hessel, and R. L. Coffman, “Therapeutic targeting of innate immunity with Toll-like receptor agonists and antagonists," Nature Medicine, vol. 13, no. 5, pp. 552-559, 2007.

[44] C. R. Wira, J. V. Fahey, C. L. Sentman, P. A. Pioli, and L. Shen, "Innate and adaptive immunity in female genital tract: cellular responses and interactions," Immunological Reviews, vol. 206, pp. 306-335, 2005.

[45] C. M. O'Connell, R. R. Ingalls, C. W. Andrews Jr., A. M. Scurlock, and T. Darville, "Plasmid-deficient Chlamydia muridarum fail to induce immune pathology and protect against oviduct disease," The Journal of Immunology, vol. 179, no. 6, pp. 40274034, 2007.

[46] B. D. Taylor, T. Darville, R. E. Ferrell, C. M. Kammerer, R. B. Ness, and C. L. Haggerty, "Variants in toll-like receptor 1 and 4 genes are associated with chlamydia trachomatis among women with pelvic inflammatory disease," Journal of Infectious Diseases, vol. 205, no. 4, pp. 603-609, 2012.

[47] A. N. Viswanathan, D. Feskanich, E. S. Schernhammer, and S. E. Hankinson, "Aspirin, NSAID, and acetaminophen use and the risk of endometrial cancer," Cancer Research, vol. 68, no. 7, pp. 2507-2513, 2008.

[48] R. E. Harris, R. T. Chlebowski, R. D. Jackson et al., "Breast cancer and nonsteroidal anti-inflammatory drugs: prospective results from the Women's Health Initiative," Cancer Research, vol. 63, no. 18, pp. 6096-6101, 2003.

[49] F. Modugno, R. B. Ness, C. Chen, and N. S. Weiss, "Inflammation and endometrial cancer: a hypothesis," Cancer Epidemiology Biomarkers and Prevention, vol. 14, no. 12, pp. 2840-2847, 2005.

[50] S. P. Hussain, L. J. Hofseth, and C. C. Harris, "Radical causes of cancer," Nature Reviews Cancer, vol. 3, no. 4, pp. 276-285, 2003.

[51] D. Forman, D. Stockton, H. Møller et al., "Cancer prevalence in the UK: results from the EUROPREVAL study," Annals of Oncology, vol. 14, no. 4, pp. 648-654, 2003.

[52] A. Macciò and C. Madeddu, "Inflammation and ovarian cancer," Cytokine, vol. 58, no. 2, pp. 133-147, 2012.

[53] M. F. Fathalla, "Incessant ovulation-a factor in ovarian neoplasia?” The Lancet, vol. 298, no. 7716, p. 163, 1971.

[54] M. F. Fathalla, "Incessant ovulation and ovarian cancer-a hypothesis re-visited," Facts, Views \& Visions in ObGyn, vol. 5, pp. 292-297, 2013.

[55] A. Maccio, G. Mantovani, E. Turnu, P. Artini, G. Contu, and A. Volpe, "Preovulatory human follicular fluid in vitro inhibits interleukin (IL)- $1 \alpha$, IL-2, and production and expression of p55 chain IL-2 receptor of lymphomonocytes," Fertility and Sterility, vol. 62, no. 2, pp. 327-332, 1994.

[56] M. Nowak, E. Glowacka, M. Szpakowski et al., "Proinflammatory and immunosuppressive serum, ascites and cyst fluid cytokines in patients with early and advanced ovarian cancer and benign ovarian tumors," Neuroendocrinology Letters, vol. 31, no. 3, pp. 375-383, 2010.

[57] T. V. Clendenen, E. Lundin, A. Zeleniuch-Jacquotte et al., "Circulating inflammation markers and risk of epithelial ovarian cancer," Cancer Epidemiology Biomarkers and Prevention, vol. 20, no. 5, pp. 799-810, 2011.

[58] G. Ferrandina, F. O. Ranelletti, L. Lauriola et al., "Cyclooxygenase-2 (COX-2), epidermal growth factor receptor (EGFR), and Her-2/neu expression in ovarian cancer," Gynecologic Oncology, vol. 85, no. 2, pp. 305-310, 2002.

[59] M. A. Altinoz and R. Korkmaz, "NF-kappaB, macrophage migration inhibitory factor and cyclooxygenase-inhibitions as likely mechanisms behind the acetaminophen- and NSAIDprevention of the ovarian cancer," Neoplasma, vol. 51, no. 4, pp. 239-247, 2004.

[60] K. J. Sales and H. N. Jabbour, "Cyclooxygenase enzymes and prostaglandins in pathology of the endometrium," Reproduction, vol. 126, no. 5, pp. 559-567, 2003.

[61] T. E. Vaskivuo, F. Stenbäck, and J. S. Tapanainen, "Apoptosis and apoptosis-related factors Bcl-2, Bax, tumor necrosis factor- $\alpha$, and NF- $\kappa$ B in human endometrial hyperplasia and carcinoma," Cancer, vol. 95, no. 7, pp. 1463-1471, 2002.

[62] M.-E. St-Germain, V. Gagnon, S. Parent, and E. Asselin, "Regulation of COX-2 protein expression by Akt in endometrial cancer cells is mediated through NF- $\kappa \mathrm{B} / \mathrm{I} \kappa \mathrm{B}$ pathway," Molecular Cancer, vol. 3, article 7, 2004.

[63] G. Ferrandina, F. Legge, F. O. Ranelletti et al., "Cyclooxygenase2 expression in endometrial carcinoma: correlation with clinicopathologic parameters and clinical outcome," Cancer, vol. 95, no. 4, pp. 801-807, 2002. 
[64] M. Tsujii, S. Kawano, S. Tsuji, H. Sawaoka, M. Hori, and R. N. DuBois, "Cyclooxygenase regulates angiogenesis induced by colon cancer cells," Cell, vol. 93, no. 5, pp. 705-716, 1998.

[65] M. Tsujii and R. N. DuBois, "Alterations in cellular adhesion and apoptosis in epithelial cells overexpressing prostaglandin endoperoxide synthase 2," Cell, vol. 83, no. 3, pp. 493-501, 1995.

[66] M. Tsujii, S. Kawano, and R. N. DuBois, "Cyclooxygenase-2 expression in human colon cancer cells increases metastatic potential," Proceedings of the National Academy of Sciences of the United States of America, vol. 94, pp. 3336-3340, 1997.

[67] V. Beral, C. Hermon, N. Munoz, and S. S. Devesa, "Cervical cancer," Cancer Surveys, vol. 19-20, pp. 265-285, 1994.

[68] J. S. Smith, R. Herrero, C. Bosetti et al., "Herpes simplex virus-2 as a human papillomavirus cofactor in the etiology of invasive cervical cancer," Journal of the National Cancer Institute, vol. 94, no. 21, pp. 1604-1613, 2002.

[69] B. Goswami, M. Rajappa, M. Sharma, and A. Sharma, "Inflammation: its role and interplay in the development of cancer, with special focus on gynecological malignancies," International Journal of Gynecological Cancer, vol. 18, no. 4, pp. 591-599, 2008.

[70] P. E. Castle, S. L. Hillier, L. K. Rabe et al., "An association of cervical inflammation with high-grade cervical neoplasia in women infected with oncogenic human papillomavirus (HPV)," Cancer Epidemiology Biomarkers and Prevention, vol. 10, no. 10, pp. 1021-1027, 2001.

[71] Y. C. Yang, C. L. Chang, Y. W. Huang, and D. Y. Wang, "Possible cofactor in cervical carcinogenesis: proliferation index of the transformation zone in cervicitis," Chang Gung Medical Journal, vol. 24, no. 10, pp. 615-620, 2001.

[72] J. R. Schwebke and M. E. Zajackowski, "Effect of concurrent lower genital tract infections on cervical cancer screening," Sexually Transmitted Infections, vol. 73, no. 5, pp. 383-386, 1997.

[73] A. Sharma, M. Rajappa, A. Saxena, and M. Sharma, "Cytokine profile in Indian women with cervical intraepithelial neoplasia and cancer cervix," International Journal of Gynecological Cancer, vol. 17, no. 4, pp. 879-885, 2007.

[74] K. J. Sales and H. N. Jabbour, "Cyclooxygenase enzymes and prostaglandins in reproductive tract physiology and pathology," Prostaglandins and Other Lipid Mediators, vol. 71, no. 3-4, pp. 97-117, 2003.

[75] D. H. Owen and D. F. Katz, "A review of the physical and chemical properties of human semen and the formulation of a semen simulant," Journal of Andrology, vol. 26, no. 4, pp. 459469, 2005.

[76] S. A. Robertson, L. R. Guerin, J. J. Bromfield, K. M. Branson, A. C. Ahlström, and A. S. Care, "Seminal fluid drives expansion of the $\mathrm{CD} 4^{+} \mathrm{CD} 25^{+} \mathrm{T}$ regulatory cell pool and induces tolerance to paternal alloantigens in mice," Biology of Reproduction, vol. 80, no. 5, pp. 1036-1045, 2009.

[77] L. M. Moldenhauer, K. R. Diener, D. M. Thring, M. P. Brown, J. D. Hayball, and S. A. Robertson, "Cross-presentation of male seminal fluid antigens elicits $\mathrm{T}$ cell activation to initiate the female immune response to pregnancy," The Journal of Immunology, vol. 182, no. 12, pp. 8080-8093, 2009.

[78] R. B. Ness and D. A. Grainger, "Male reproductive proteins and reproductive outcomes," American Journal of Obstetrics \& Gynecology, vol. 198, no. 6, pp. 620.el-620.e4, 2008.

[79] M. Hamberg and B. Samuelsson, "Prostaglandins in human seminal plasma. Prostaglandins and related factors 46," The Journal of Biological Chemistry, vol. 241, no. 2, pp. 257-263, 1966.
[80] A. A. Templeton, I. Cooper, and R. W. Kelly, "Prostaglandin concentrations in the semen of fertile men," Journal of Reproduction and Fertility, vol. 52, no. 1, pp. 147-150, 1978.

[81] E. H. Oliw, H. Sprecher, and M. Hamberg, "Isolation of two novel E prostaglandins in human seminal fluid," The Journal of Biological Chemistry, vol. 261, no. 6, pp. 2675-2683, 1986.

[82] H. J. Schuberth, U. Taylor, H. Zerbe, D. Waberski, R. Hunter, and D. Rath, "Immunological responses to semen in the female genital tract," Theriogenology, vol. 70, no. 8, pp. 1174-1181, 2008.

[83] K. J. Sales, A. A. Katz, B. Howard, R. P. Soeters, R. P. Millar, and H. N. Jabbour, "Cyclooxygenase-1 is up-regulated in cervical carcinomas: autocrine/paracrine regulation of cyclooxygenase2, prostaglandin $\mathrm{E}$ receptors, and angiogenic factors by cyclooxygenase-1," Cancer Research, vol. 62, no. 2, pp. 424-432, 2002.

[84] K. J. Sales, A. A. Katz, M. Davis et al., "Cyclooxygenase-2 expression and prostaglandin E2 synthesis are up-regulated in carcinomas of the cervix: a possible autocrine/paracrine regulation of neoplastic cell function via EP2/EP4 receptors," Journal of Clinical Endocrinology and Metabolism, vol. 86, no. 5, pp. 2243-2249, 2001.

[85] D. W. Fitzgerald, K. Bezak, O. Ocheretina et al., "The effect of HIV and HPV coinfection on cervical COX-2 expression and systemic prostaglandin $\mathrm{E}_{2}$ levels," Cancer Prevention Research, vol. 5, no. 1, pp. 34-40, 2012.

[86] N. Dumais, "Emerging roles of prostaglandins in HIV-1 transcription," in HIV and AIDS-Updates on Biology, Immunology, Epidemiology and Treatment Strategies, D. N. Dumais, Ed., pp. 346-370, InTech, Rijeka, Croatia, 2011.

[87] N. Yamamoto, S. Harada, and H. Nakashima, "Substances affecting the infection and replication of human immunodeficiency virus (HIV)," AIDS Research, vol. 2, supplement 1, pp. S183-S189, 1986.

[88] T. Joseph, I. A. Zalenskaya, L. C. Sawyer, N. Chandra, and G. F. Doncel, "Seminal plasma induces prostaglandin-endoperoxide synthase (PTGS) 2 expression in immortalized human vaginal cells: involvement of semen prostaglandin E2 in PTGS2 upregulation," Biology of Reproduction, vol. 88, no. 1, article 13, 2013.

[89] A. O. Adefuye, K. J. Sales, and A. A. Katz, "Seminal plasma induces the expression of IL- $1 \alpha$ in normal and neoplastic cervical cells via EP2/EGFR/PI3K/AKT pathway," Journal of Molecular Signaling, vol. 9, article 8, 2014.

[90] K. J. Sales, A. Adefuye, L. Nicholson, and A. A. Katz, "CCR5 expression is elevated in cervical cancer cells and is up-regulated by seminal plasma," Molecular Human Reproduction, vol. 20, no. 11, Article ID gau063, pp. 1144-1157, 2014.

[91] D. Waberski, R. Claassen, T. Hahn et al., "LH profile and advancement of ovulation after transcervical infusion of seminal plasma at different stages of oestrus in gilts," Journal of Reproduction and Fertility, vol. 109, no. 1, pp. 29-34, 1997.

[92] G. P. Adams, M. H. Ratto, W. Huanca, and J. Singh, "Ovulationinducing factor in the seminal plasma of alpacas and llamas," Biology of Reproduction, vol. 73, no. 3, pp. 452-457, 2005.

[93] M. Brannstrom, N. Bonello, L. J. Wang, and R. J. Norman, "Effects of tumour necrosis factor $\alpha$ (TNF $\alpha$ ) on ovulation in the rat ovary," Reproduction, Fertility and Development, vol. 7, no. 1, pp. 67-73, 1995.

[94] I. Guleria and M. H. Sayegh, "Maternal acceptance of the fetus: true human tolerance," The Journal of Immunology, vol. 178, no. 6, pp. 3345-3351, 2007. 
[95] V. R. Aluvihare, M. Kallikourdis, and A. G. Betz, "Regulatory T cells mediate maternal tolerance to the fetus," Nature Immunology, vol. 5, no. 3, pp. 266-271, 2004.

[96] S. Beissert, A. Schwarz, and T. Schwarz, "Regulatory T cells," Journal of Investigative Dermatology, vol. 126, no. 1, pp. 15-24, 2006.

[97] F. Baratelli, Y. Lin, L. Zhu et al., "Prostaglandin E2 induces FOXP3 gene expression and $\mathrm{T}$ regulatory cell function in human $\mathrm{CD}^{+} \mathrm{T}$ cells," Journal of Immunology, vol. 175, no. 3, pp. 1483-1490, 2005.

[98] W. Chen, W. Jin, N. Hardegen et al., "Conversion of peripheral $\mathrm{CD} 4^{+} \mathrm{CD} 25^{-}$naive $\mathrm{T}$ Cells to $\mathrm{CD} 4^{+} \mathrm{CD} 25^{+}$regulatory T Cells by TGF- $\beta$ induction of transcription factor Foxp3," Journal of Experimental Medicine, vol. 198, no. 12, pp. 1875-1886, 2003.

[99] J. Kavanagh, A. J. Kelly, and J. Thomas, "Sexual intercourse for cervical ripening and induction of labour," Cochrane Database of Systematic Reviews, no. 2, Article ID CD003093, 2001.

[100] J. W. Sublett and J. A. Bernstein, "Seminal plasma hypersensitivity reactions: an updated review," Mount Sinai Journal of Medicine, vol. 78, no. 5, pp. 803-809, 2011.

[101] D. Ghosh and J. A. Bernstein, "Systemic and localized seminal plasma hypersensitivity patients exhibit divergent immunologic characteristics," Journal of Allergy and Clinical Immunology, vol. 134, no. 4, pp. 969-972, 2014.

[102] S. Weidinger, J. Ring, and F. M. Köhn, "IgE-mediated allergy against human seminal plasma," Chemical Immunology and Allergy, vol. 88, pp. 128-138, 2005.

[103] S. J. Bashir and H. I. Maibach, "Contact urticaria syndrome," Irritant Dermatitis, pp. 63-70, 2006.

[104] S. A. Robertson, "Seminal plasma and male factor signalling in the female reproductive tract," Cell and Tissue Research, vol. 322, no. 1, pp. 43-52, 2005.

[105] H. N. Jabbour and K. J. Sales, "Prostaglandin receptor signalling and function in human endometrial pathology," Trends in Endocrinology and Metabolism, vol. 15, no. 8, pp. 398-404, 2004.

[106] K. J. Sales, S. C. Boddy, and H. N. Jabbour, "F-prostanoid receptor alters adhesion, morphology and migration of endometrial adenocarcinoma cells," Oncogene, vol. 27, no. 17, pp. 2466-2477, 2008.

[107] P. G. Ney, "The intravaginal absorption of male generated hormones and their possible effect on female behaviour," Medical Hypotheses, vol. 20, no. 2, pp. 221-231, 1986.

[108] K. J. Sales, A. A. Katz, R. P. Millar, and H. N. Jabbour, "Seminal plasma activates cyclooxygenase-2 and prostaglandin E2 receptor expression and signalling in cervical adenocarcinoma cells," Molecular Human Reproduction, vol. 8, no. 12, pp. 1065-1070, 2002.

[109] M. Muller, K. J. Sales, A. A. Katz, and H. N. Jabbour, "Seminal plasma promotes the expression of tumorigenic and angiogenic genes in cervical adenocarcinoma cells via the E-series prostanoid 4 receptor," Endocrinology, vol. 147, no. 7, pp. 33563365, 2006.

[110] J. R. Sutherland, K. J. Sales, H. N. Jabbour, and A. A. Katz, "Seminal plasma enhances cervical adenocarcinoma cell proliferation and tumour growth in vivo," PLoS ONE, vol. 7, no. 3, Article ID e33848, 2012.

[111] D. Wang and R. N. Dubois, "Eicosanoids and cancer," Nature Reviews Cancer, vol. 10, no. 3, pp. 181-193, 2010.

[112] D. Hwang, D. Scollard, J. Byrne, and E. Levine, "Expression of cyclooxygenase-1 and cyclooxygenase- 2 in human breast cancer," Journal of the National Cancer Institute, vol. 90, no. 6, pp. 455-460, 1998.
[113] K. J. Sales, J. R. Sutherland, H. N. Jabbour, and A. A. Katz, “Seminal plasma induces angiogenic chemokine expression in cervical cancer cells and regulates vascular function," Biochimica et Biophysica Acta (BBA)-Molecular Cell Research, vol. 1823, no. 10, pp. 1789-1795, 2012.

[114] S. P. Herbert, A. F. Odell, S. Ponnambalam, and J. H. Walker, "The confluence-dependent interaction of cytosolic phospholipase A 2- $\alpha$ with annexin A1 regulates endothelial cell prostaglandin E2 generation," Journal of Biological Chemistry, vol. 282, no. 47, pp. 34469-34478, 2007.

[115] M. Murakami, H. Naraba, T. Tanioka et al., "Regulation of prostaglandin E2 biosynthesis by inducible membrane-associated prostaglandin E2 synthase that acts in concert with cyclooxygenase-2," The Journal of Biological Chemistry, vol. 275, no. 42, pp. 32783-32792, 2000.

[116] L. Forsberg, L. Leeb, S. Thorén, R. Morgenstern, and P.-J. Jakobsson, "Human glutathione dependent prostaglandin E synthase: gene structure and regulation," FEBS Letters, vol. 471, no. 1, pp. 78-82, 2000.

[117] R. Jones, L.-A. Adel-Alvarez, O. R. Alvarez, R. Broaddus, and S. Das, "Arachidonic acid and colorectal carcinogenesis," Molecular and Cellular Biochemistry, vol. 253, no. 1-2, pp. 141149, 2003.

[118] J. R. Mann, M. G. Backlund, F. G. Buchanan et al., "Repression of prostaglandin dehydrogenase by epidermal growth factor and snail increases prostaglandin $\mathrm{E}_{2}$ and promotes cancer progression," Cancer Research, vol. 66, no. 13, pp. 6649-6656, 2006.

[119] D. Wang and R. N. DuBois, "Pro-inflammatory prostaglandins and progression of colorectal cancer," Cancer Letters, vol. 267, no. 2, pp. 197-203, 2008.

[120] C. M. Ensor and H.-H. Tai, "15-Hydroxyprostaglandin dehydrogenase," Journal of Lipid Mediators and Cell Signalling, vol. 12, no. 2-3, pp. 313-319, 1995.

[121] S. Tseng-Rogenski, J. Gee, K. W. Ignatoski et al., "Loss of 15hydroxyprostaglandin dehydrogenase expression contributes to bladder cancer progression," American Journal of Pathology, vol. 176, no. 3, pp. 1462-1468, 2010.

[122] Z. Liu, X. Wang, Y. Lu et al., "Expression of 15-PGDH is downregulated by COX-2 in gastric cancer," Carcinogenesis, vol. 29, no. 6, pp. 1219-1227, 2008.

[123] I. Wolf, J. O’Kelly, T. Rubinek et al., "15-Hydroxyprostaglandin dehydrogenase is a tumor suppressor of human breast cancer," Cancer Research, vol. 66, no. 15, pp. 7818-7823, 2006.

[124] S.-J. Myung, R. M. Rerko, M. Yan et al., "15-Hydroxyprostaglandin dehydrogenase is an in vivo suppressor of colon tumorigenesis," Proceedings of the National Academy of Sciences of the United States of America, vol. 103, no. 32, pp. 12098-12102, 2006.

[125] B. Frank, B. Hoeft, M. Hoffmeister et al., "Association of hydroxyprostaglandin dehydrogenase 15-(NAD) (HPGD) variants and colorectal cancer risk," Carcinogenesis, vol. 32, no. 2, pp. 190196, 2011.

[126] M. Yan, S.-J. Myung, S. P. Fink et al., "15-Hydroxyprostaglandin dehydrogenase inactivation as a mechanism of resistance to celecoxib chemoprevention of colon tumors," Proceedings of the National Academy of Sciences of the United States of America, vol. 106, no. 23, pp. 9409-9413, 2009.

[127] Y. I. Cha and R. N. DuBois, "NSAIDs and cancer prevention: targets downstream of COX-2," Annual Review of Medicine, vol. 58, pp. 239-252, 2007. 
[128] W. R. Henderson Jr., "The role of leukotrienes in inflammation," Annals of Internal Medicine, vol. 121, no. 9, pp. 684-697, 1994.

[129] H. Hasturk, A. Kantarci, E. Goguet-Surmenian et al., "Resolvin E1 regulates inflammation at the cellular and tissue level and restores tissue homeostasis in vivo," Journal of Immunology, vol. 179, no. 10, pp. 7021-7029, 2007.

[130] B. K. Lam, "Leukotriene C4 synthase," Prostaglandins Leukotrienes and Essential Fatty Acids, vol. 69, no. 2-3, pp. 111-116, 2003.

[131] C. Brink, S.-E. Dahlen, J. Drazen et al., "International Union of Pharmacology XXXVII. Nomenclature for leukotriene and lipoxin receptors," Pharmacological Reviews, vol. 55, no. 1, pp. 195-227, 2003.

[132] V. Capra, "Molecular and functional aspects of human cysteinyl leukotriene receptors," Pharmacological Research, vol. 50, no. 1, pp. 1-11, 2004.

[133] J. F. Öhd, C. K. Nielsen, J. Campbell, G. Landberg, H. Löfberg, and A. Sjölander, "Expression of the leukotriene D4 receptor CysLT1, COX-2, and other cell survival factors in colorectal adenocarcinomas," Gastroenterology, vol. 124, no. 1, pp. 57-70, 2003.

[134] M. Matsuyama, T. Hayama, K. Funao et al., "Overexpression of cysteinyl LT1 receptor in prostate cancer and CysLT1R antagonist inhibits prostate cancer cell growth through apoptosis," Oncology Reports, vol. 18, no. 1, pp. 99-104, 2007.

[135] C. A. Borgoño and E. P. Diamandis, "The emerging roles of human tissue kallikreins in cancer," Nature Reviews Cancer, vol. 4, no. 11, pp. 876-890, 2004.

[136] N. Emami and E. P. Diamandis, "New insights into the functional mechanisms and clinical applications of the kallikreinrelated peptidase family," Molecular Oncology, vol. 1, no. 3, pp. 269-287, 2007.

[137] D. Proud and A. P. Kaplan, "Kinin formation: mechanisms and role in inflammatory disorders," Annual Review of Immunology, vol. 6, pp. 49-83, 1988.

[138] D. Regoli and J. Barabé, "Pharmacology of bradykinin and related kinins," Pharmacological Reviews, vol. 32, no. 1, pp. 1-46, 1980.

[139] J. B. Calixto, R. Medeiros, E. S. Fernandes, J. Ferreira, D. A. Cabrini, and M. M. Campos, "Kinin B 1 receptors: key Gprotein-coupled receptors and their role in inflammatory and painful processes," British Journal of Pharmacology, vol. 143, no. 7, pp. 803-818, 2004.

[140] X. Li, S. Jiang, and R. I. Tapping, "Toll-like receptor signaling in cell proliferation and survival," Cytokine, vol. 49, no. 1, pp. 1-9, 2010.

[141] S. Akira and K. Takeda, "Toll-like receptor signalling," Nature Reviews Immunology, vol. 4, no. 7, pp. 499-511, 2004.

[142] W. Xie, Y. Wang, Y. Huang, H. Yang, J. Wang, and Z. Hu, "Toll-like receptor 2 mediates invasion via activating NF- $\kappa \mathrm{B}$ in MDA-MB-231 breast cancer cells," Biochemical and Biophysical Research Communications, vol. 379, no. 4, pp. 1027-1032, 2009.

[143] C.-Y. Hsieh, S.-L. You, C.-L. Kao, and C.-J. Chen, "Reproductive and infectious risk factors for invasive cervical cancer in Taiwan," Anticancer Research, vol. 19, no. 5, pp. 4495-4500, 1999.

[144] L. M. Coussens and Z. Werb, "Inflammation and cancer," Nature, vol. 420, no. 6917, pp. 860-867, 2002.

[145] F. Balkwill, K. A. Charles, and A. Mantovani, "Smoldering and polarized inflammation in the initiation and promotion of malignant disease," Cancer Cell, vol. 7, no. 3, pp. 211-217, 2005.
[146] A. Mantovani, “Cancer: inflaming metastasis," Nature, vol. 457, no. 7225, pp. 36-37, 2009.

[147] S. Ali and G. Lazennec, "Chemokines: novel targets for breast cancer metastasis," Cancer and Metastasis Reviews, vol. 26, no. 3-4, pp. 401-420, 2007.

[148] D. Vindrieux, P. Escobar, and G. Lazennec, "Emerging roles of chemokines in prostate cancer," Endocrine-Related Cancer, vol. 16, no. 3, pp. 663-673, 2009.

[149] A. Mantovani, P. Allavena, S. Sozzani, A. Vecchi, M. Locati, and A. Sica, "Chemokines in the recruitment and shaping of the leukocyte infiltrate of tumors," Seminars in Cancer Biology, vol. 14, no. 3, pp. 155-160, 2004.

[150] J. C. Chen, B. A. Johnson, D. W. Erikson et al., "Seminal plasma induces global transcriptomic changes associated with cell migration, proliferation and viability in endometrial epithelial cells and stromal fibroblasts," Human Reproduction, vol. 29, no. 6, pp. 1255-1270, 2014.

[151] J. E. Schjenken, D. J. Glynn, D. J. Sharkey, and S. A. Robertson, "TLR4 signaling is a major mediator of the female tract response to seminal fluid in mice," Biology of Reproduction, vol. 93, article 68, 2015.

[152] H. Wakabayashi, P. G. Cavanaugh, and G. L. Nicolson, "Purification and identification of mouse lung microvessel endothelial cell-derived chemoattractant for lung-metastasizing murine RAW117 large-cell lymphoma cells: identification as mouse monocyte chemotactic protein 1," Cancer Research, vol. 55, no. 19, pp. 4458-4464, 1995.

[153] D. Wang, H. Wang, J. Brown et al., "CXCL1 induced by prostaglandin E2 promotes angiogenesis in colorectal cancer," Journal of Experimental Medicine, vol. 203, no. 4, pp. 941-951, 2006.

[154] G. Castrilli, D. Tatone, M. G. Diodoro, S. Rosini, M. Piantelli, and P. Musiani, "Interleukin $1 \alpha$ and interleukin 6 promote the in vitro growth of both normal and neoplastic human cervical epithelial cells," British Journal of Cancer, vol. 75, no. 6, pp. 855859, 1997.

[155] X. Chen, S. Han, S. Wang et al., "Interactions of IL-12A and IL$12 \mathrm{~B}$ polymorphisms on the risk of cervical cancer in Chinese women," Clinical Cancer Research, vol. 15, no. 1, pp. 400-405, 2009.

[156] A. J. Puren, G. Fantuzzi, Y. Gu, M. S.-S. Su, and C. A. Dinarello, "Interleukin-18 (IFN $\gamma$-inducing factor) induces IL-8 and IL-1 $\beta$ via TNF $\alpha$ production from non-CD14+ human blood mononuclear cells," The Journal of Clinical Investigation, vol. 101, no. 3, pp. 711-721, 1998.

[157] G. Trinchieri, "Interleukin-12 and the regulation of innate resistance and adaptive immunity," Nature Reviews Immunology, vol. 3, no. 2, pp. 133-146, 2003.

[158] T. D. de Gruijl, H. J. Bontkes, A. J. C. Van den Muysenberg et al., "Differences in cytokine mRNA profiles between premalignant and malignant lesions of the uterine cervix," European Journal of Cancer, vol. 35, no. 3, pp. 490-497, 1999.

[159] K. A. Paschos, D. Canovas, and N. C. Bird, "The role of cell adhesion molecules in the progression of colorectal cancer and the development of liver metastasis," Cellular Signalling, vol. 21, no. 5, pp. 665-674, 2009. 


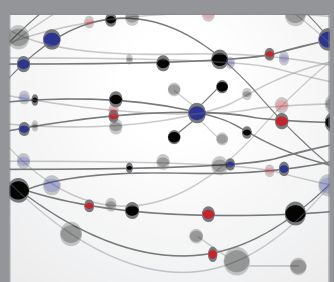

The Scientific World Journal
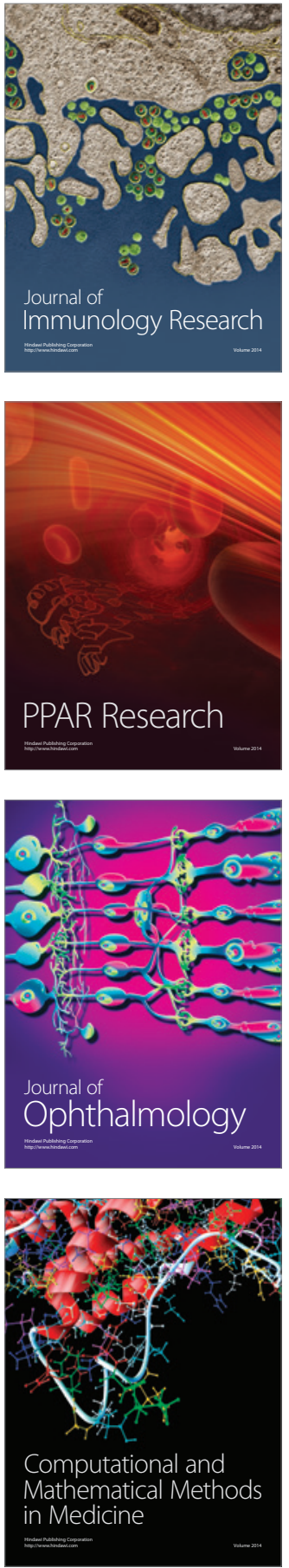

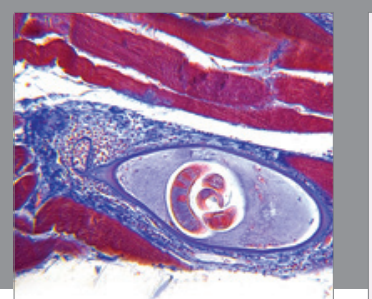

Gastroenterology Research and Practice

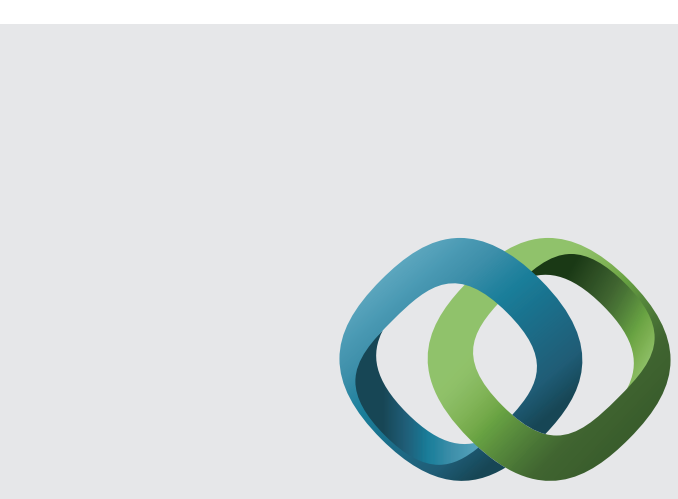

\section{Hindawi}

Submit your manuscripts at

http://www.hindawi.com
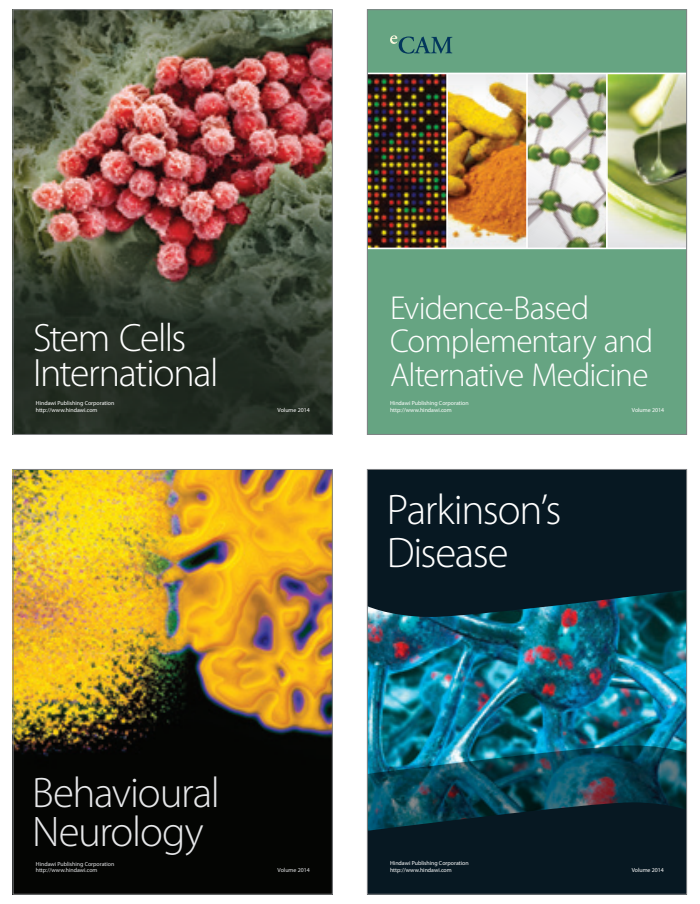
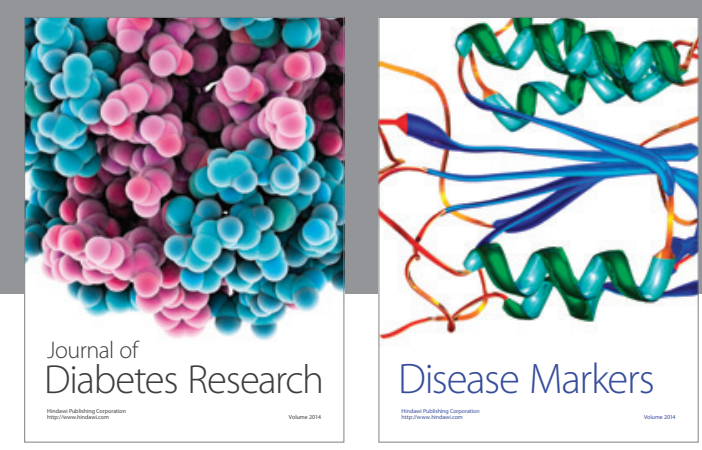

Disease Markers
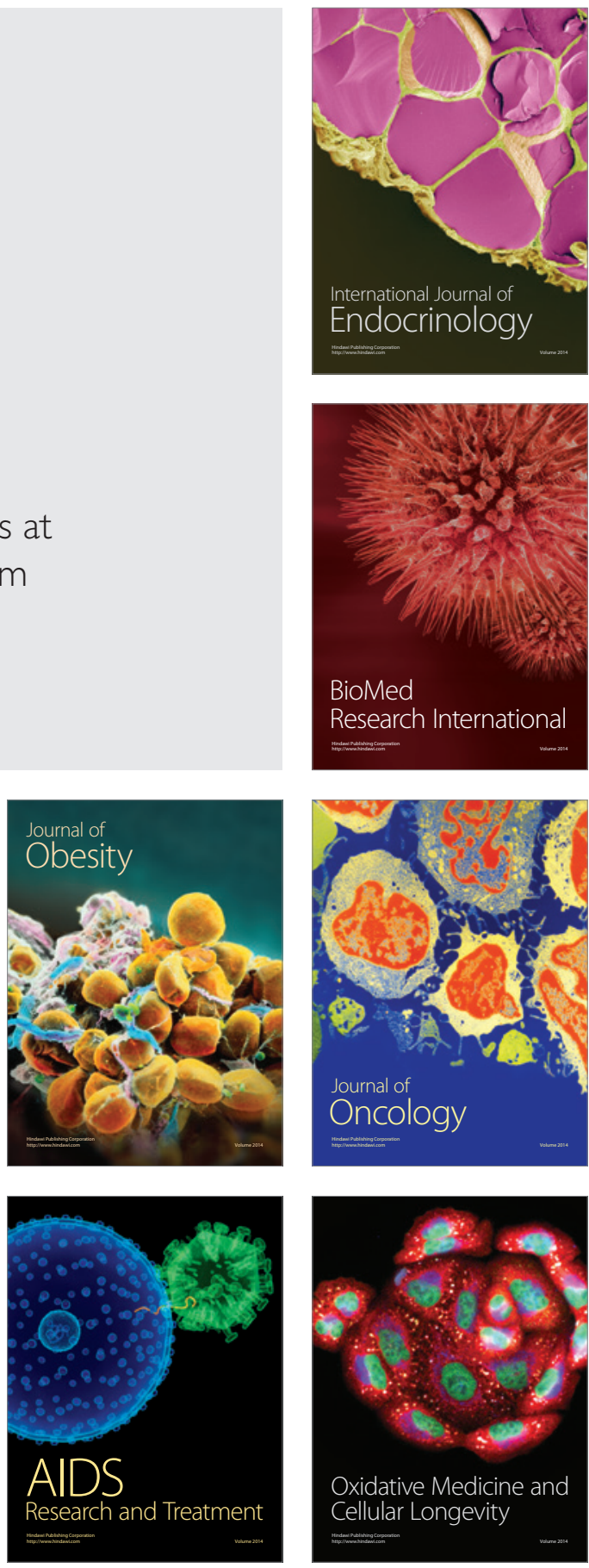